\title{
COMPARISON OF ANALYTICAL METHODS FOR ESTIMATION OF EARLY-AGE THERMAL-SHRINKAGE STRESSES IN RC WALLS
}

\author{
B. KLEMCZAK ${ }^{1}$, A. KNOPPIK-WRÓBEL ${ }^{2}$
}

\begin{abstract}
The volume changes caused by coupled temperature and moisture variations in early-age concrete elements lead to formation of stresses. If a restraint exists along the contact surface of mature concrete against which a new concrete element has been cast, generated stresses are mostly of a restraint origin. In engineering practice a wide range of externally restrained concrete elements can be distinguished such as tank walls or bridge abutments cast against an old set foundation, in which early-age cracking may endanger their durability or functionality. Therefore, for years methods were being developed to predict early-age stresses and cracking risk of externally restrained concrete elements subjected to early-age thermal-moisture effects. The paper presents the comparative study of the most recognised analytical approaches: the method proposed in EC2, the method proposed by ACI Committee 207 and the method developed at the Luleå University of Technology.
\end{abstract}

Key words: RC wall, thermal-shrinkage stresses, degree of restraint, analytical models.

\section{INTRODUCTION}

Thermal and shrinkage stresses arise in early-age concrete as a result of volume changes due to the temperature and moisture variations during hardening process (Fig. 1). The variations of concrete temperature during curing are connected with an exothermic nature of the chemical reaction between cement and water. In structural elements with thin sections the generated heat dissipates quickly and causes no problem. In thicker sections the internal temperature can reach a significant level. Furthermore, due to the poor thermal conductivity of concrete, high temperature gradients may occur between the interior and the surface of thick structural elements. Concrete curing is also accompanied with moisture exchange with the environment in conditions of variable temperature. The loss of water trough evaporation at the surface of element results in shrinkage, which is classified as an external drying shrinkage. There is also internal drying resulting from the reduction in material volume as water is consumed by hydration, which is classified as

1 PhD, Dsc., Associate Prof., Silesian University of Technology, Akademicka 5, 44-100 Gliwice, Barbara.Klemczak@polsl.pl

2 Msc., PhD student, Silesian University of Technology, Akademicka 5, 44-100 Gliwice, Agnieszka. Knoppik-Wrobel@polsl.pl 
autogenous shrinkage. Additionally, the chemical shrinkage is also distinguished which occurs because the volume of hydration products is less than original volume of cement and water. The volume changes due to the temperature and moisture variations have consequences in arising thermal-shrinkage stresses in a concrete element.

a)

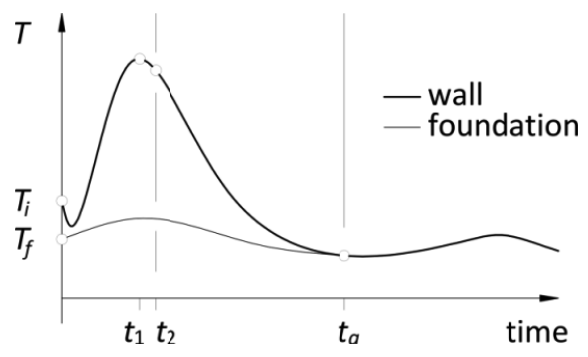

b)

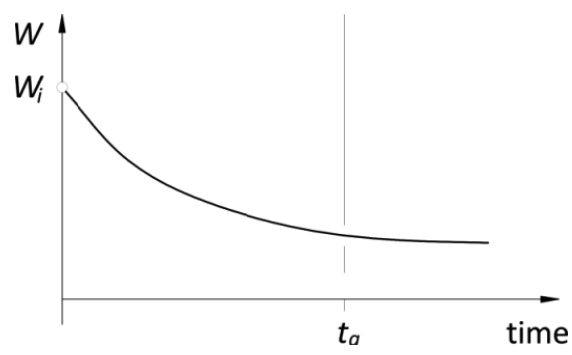

Fig. 1. Temperature (a) and moisture content

(b) development in time for an externally restrained concrete wall [7].

Thermal-shrinkage stresses in externally restrained elements result from a coupled action of self-induced and restraint stresses with a predominant role of restraint stresses. Self-induced stresses occur, too, but their influence is much smaller. This is mainly the result of temperature and moisture concentration distribution within the wall: even though the difference is observed, it is of a relatively small magnitude (KLEMCZAK [1], KNOPPIK-WRóBEL [2], ZYCh [3]).

Self-induced stresses originate from the material itself due to the internal restraint caused by temperature and moisture gradients. In an internally restrained element stress development is characterised by formation of compressive stresses in the interior and tensile stresses on the surface of the element in the heating phase while in the cooling phase stress body inversion in observed.

Restraint stresses result from external limitation of deformation, usually caused by mature concrete of previously cast layers. Their magnitude depends on a degree of restraint induced by an older part against a newer part of the structure. The degree of restraint is expressed in a form of an restraint factor, $\gamma_{R}$, which in any point of the element is defined as a ratio between the stress generated in an unrestrained element $\sigma$ to the fixation stress $\sigma^{\text {fix }}$ ([4], [5], NiLSSON [6], LARSON [7]):

$$
\gamma_{R}=\frac{\sigma}{\sigma^{\text {fix }}}
$$

and may take values between 0 at no restraint to 1 at total fixation. It varies throughout the element with the maximum value at the joint in the mid span and decreasing towards 
free edges of the element. The degree of restrain of the element depends predominantly on the length-to-height ratio of the element, $L / H$, but also on the ratio of stiffness of a newly cast (wall) and a mature (foundation) part. Restraint stresses have different character than self-induced stresses: in the heating phase almost the whole volume of the element is subjected to compression while in the cooling phase tensile stresses occur. The discussed tensile stresses in the cooling phase can reach a significant level and cracks can be induced in the structure. These cracks, especially deep or through cracks, may adversely affect the serviceability, lifespan or even bearing capacity of a concrete structure.

Some methods were developed to assess the influence of the degree of restraint on the character and values of tensile stresses occurring in the phase of the element cooling. The methods are based on the concept of the restraint factor. In this paper three most known approaches are presented: the method given in Eurocode 2 - Part 3 [4], the method proposed by ACI Committee 207 in the Report on Thermal and Volume Change Effects on Cracking of Mass Concrete [5] and the method developed at the Luleå University of Technology (NILSSON [6], LARSON [7]).

\section{EUROCODE 2 APPROACH}

Eurocode 2 - Design of concrete structures in Part 3: Liquid retaining and containment structures [4] presents a simple, engineering method for determination of restraint stresses generated by self-induced strains and resulting risk of cracking in externally restrained walls on the example of tanks and silos. The information and requirements provided in Part 3 should be read in conjunction with the requirements stated in Part 1-1: General rules and rules for buildings [8].

\subsection{Temperature AND SHRINKAge-INDUCED VOlume CHANGES}

The standard does not provide specific suggestions for determination of early-age thermal-moisture effects. It is only stated that where conditions during the construction phase are considered to be significant, the heat evolution characteristics for a particular cement should generally be obtained from tests. The actual heat evolution should be determined taking account of the expected conditions during the early life of the member (e.g. curing, ambient conditions). The maximum temperature rise and the time of occurrence after casting should be established from the mix design, the nature of the formwork, the ambient conditions and the boundary conditions.

For determination of restraint strains or stresses it is stated that assumption of elastic behaviour of concrete is satisfactorily precise and that the effect of creep can be considered by means of effective (reduced) modulus of elasticity. To estimate the magnitude of the restraint strain free thermal and shrinkage strains must be determined and the restraint must be known. The total thermal-shrinkage strain $\varepsilon_{\mathrm{tot}}(t)$ is a sum of thermal strain $\varepsilon_{T}(t)$ and shrinkage strain $\varepsilon_{c s}(t)$ : 


$$
\varepsilon_{\mathrm{tot}}(t)=\varepsilon_{T}(t)+\varepsilon_{c s}(t)
$$

where:

$$
\begin{aligned}
\varepsilon_{T}=\alpha_{T} \cdot \Delta T- & \text { thermal strain, } \Delta T \text { is the temperature difference, }{ }^{\circ} \mathrm{C} ; \\
\varepsilon_{c s}=\varepsilon_{c d}+\varepsilon_{c a}- & \text { total shrinkage strain: drying shrinkage and autogenous shrinkage } \\
& \text { strain; } \\
\alpha_{T} & \text { coefficient of thermal expansion, } 1 /{ }^{\circ} \mathrm{C} \text {; the basic value of } \alpha_{T} \text { is given as } \\
& \text { equal to } 10 \cdot 10^{-6} /{ }^{\circ} \mathrm{C} \text { but the standard emphasises variability of thermal } \\
& \text { expansion coefficient depending on the type of aggregate and moisture } \\
& \text { content in concrete mix. }
\end{aligned}
$$

\subsection{RESTRAINT STRESSES}

The stress at any level $y$ in uncracked section due to translational and rotational restraint of the element can be calculated based on the known imposed strain from the equation:

$$
\sigma(y)=E_{c m, e f f} \cdot\left(\varepsilon_{i}(y)-\varepsilon_{a}(y)\right)
$$

in which the actual strain at level $y, \varepsilon_{a}(y)$, is given by:

$$
\varepsilon_{a}(y)=\left(1-R_{a x}\right) \cdot \varepsilon_{i_{a v}}+\left(1+R_{m}\right) \cdot \frac{1}{r} \cdot\left(y-y_{\text {cen }}\right)
$$

where:

$R_{a x} \quad$ - factor defining the degree of external axial restraint provided by elements attached to the element considered. The restraint factors may be calculated on the base of the stiffness of the element considered and the members attached to it. Alternatively, practical axial restraint factors for common situations may be taken from Fig. 2;

$R_{m} \quad$ - factor defining the degree of moment restraint provided by elements attached to the element considered. In most common cases $R_{m}$ may be taken as 1.0 ;

$E_{c m, e f f}-$ effective modulus of elasticity of concrete allowing for creep as appropriate;

$\varepsilon_{i_{a v}}-$ average imposed strain in the element (i.e. the average strain which would occur if the member was completely unrestrained);

$\varepsilon_{a}(y)$ - actual strain at level $y$;

$\varepsilon_{i}(y) \quad$ - imposed strain at level $y$;

$y \quad-$ height from joint plane to section;

$y_{\text {cen }}-$ height from joint plane to section centroid;

$1 / r \quad$ - curvature of joint plane (if the restraining element is flexible). 


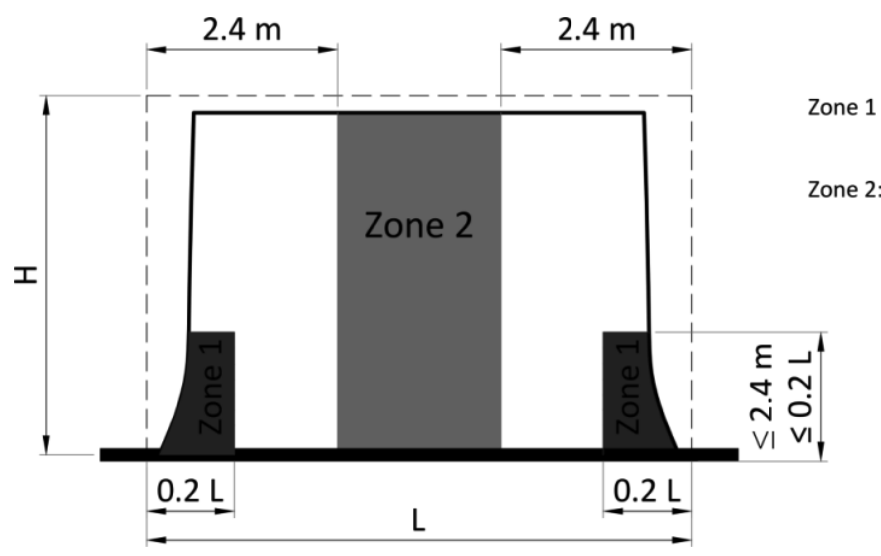

vertical restraint factors $=0.25$

horizontal restraint factors $=0$

vertical restraint factors $=0$

horizontal restraint factors - acc. to table

Fig. 2. Axial restraint factor $R_{a x}$ in element restrain along one edge [4].

In the simplified approach when no rotational restraint is considered, the problem can be reduced to a planar problem (no distribution of strain at the thickness of cross-section is considered), $\varepsilon_{i}=\varepsilon_{i_{a v}}$. The average imposed strain can be taken as total thermal-shrinkage strain $\varepsilon_{\text {tot }}$ calculated acc. to Eq. (2.1). The stress at any level $y$ of centre section can be then conventionally expressed with use of the restraint factor:

$$
\gamma_{R}=R_{a x}
$$

as:

$$
\sigma=R_{a x} \cdot E_{c m, e f f} \cdot \varepsilon_{\mathrm{tot}}
$$

The values of material parameters must be defined for the actual age of concrete corrected for temperature effects and influence of creep. The change of material parameters can be taken according to [8]. The mean modulus of elasticity development is given by the equation:

$$
E_{c m}(t)=\left[\frac{f_{c m}(t)}{f_{c m}}\right]^{0.3} \cdot E_{c m}
$$

where:

$E_{c m}$ - mean 28-day modulus of elasticity of concrete, GPa;

$f_{c m}$ - mean 28-day compressive strength of concrete, MPa;

$f_{c m}(t)$ - mean compressive strength of concrete taking into consideration concrete age, $\mathrm{MPa}$, acc. to the equation: $f_{c m}(t)=\beta_{c c}(t) \cdot f_{c m}$;

$\beta_{c c}(t)$ - coefficient dependent on the age of concrete. 
The effect of creep can be included by reduction of the modulus of elasticity, however, it is not stated neither in [4] nor in [8] how the effect of creep on stress relaxation in early-age concrete should be considered. Nevertheless, it is given that for concrete heated prior to loading, the creep coefficient may be assumed to increase with increase in temperature above normal (assumed as $20^{\circ} \mathrm{C}$ ) by the appropriate factor given [4], hence the effect of self-heating of concrete due to hydration in construction stages can be included in calculations.

\section{ACI COMMITTEE 207 APPROACH}

The instructions given in the Report 207.2R-07 [6] are primarily concerned with control of cracking in elements that occurs mainly from thermal contraction with restraint, hence, it focuses on evaluation of thermal behaviour of massive concrete structures. Moisture changes are also discussed but to a limited extent. Other volume changes like alkali-aggregate expansion, autogenous shrinkage and changes due to expansive cement are not considered. The report presents a detailed discussion on the effects of heat generation and volume changes in massive concrete elements, methods to compute heat dissipation and volume changes as well as to determine mass and surface gradient stresses.

\subsection{TemperatuRe AND SHRINKAge-INDUCED VOLUME CHANGeS}

The maximum effective temperature change depends on four basic temperature determinations: the effective placing temperature, the final or operating temperature of concrete, the temperature rise of concrete due to hydration and the equivalent temperature change to compensate for drying shrinkage. The volume change that leads to thermal cracking results from the temperature difference between the peak temperature of concrete attained during early hydration and the minimum temperature to which the element will be subjected under service conditions. The report assumes a condition of no initial stress as the initial hydration temperature rise produces little stress in concrete - at early age the modulus of elasticity of concrete is so small that compressive stresses induced by the rise in temperature are insignificant even in zones of full restraint and, in addition, are relaxed by a high rate of creep. The thermal volume change $\Delta V$ can be computed as:

$$
\Delta V=\left\lfloor T_{f}-\left(T_{i}+T_{a d}\right)+T_{e n v}\right\rfloor \cdot \alpha_{T}
$$

where:

$T_{f}$ - final stable temperature of concrete, ${ }^{\circ} \mathrm{C}$;

$T_{i} \quad$ - initial placing temperature of concrete, ${ }^{\circ} \mathrm{C}$; 
$T_{a d}$ - adiabatic temperature rise of concrete, ${ }^{\circ} \mathrm{C}$;

$T_{e n v}$ - temperature change due to heat added or subtracted from concrete due to environmental conditions, ${ }^{\circ} \mathrm{C}$;

$\alpha_{T}-$ coefficient of thermal expansion of concrete, $1 /{ }^{\circ} \mathrm{C}$.

The report proposes methods for determination of each of the components. If no special treatment was applied, the placing temperature can be taken as equal to the air temperature at the moment of placement. The minimum expected final temperature of a concrete element (final temperature in service) can be taken as the average minimum exposure temperature occurring during a period of approximately 1 week. Instructions are given to estimate adiabatic temperature rise if no specific data are provided concerning heat generation in massive concrete elements for a given type and amount of cement contained. Nevertheless, it is stated that the data should be taken directly from laboratory tests for specific cements.

Drying shrinkage was expressed in terms of equivalent change in concrete temperature $T_{D S}$, according to the equation:

$$
T_{D S}=\left(30-\frac{12 V}{S}\right) \cdot\left(\frac{W_{u}-125}{100}\right)
$$

where:

$W_{u}$ - water content of fresh concrete, $\mathrm{lb} / \mathrm{yd}^{3}$, but not less than $225 \mathrm{lb} / \mathrm{yd}^{3}\left(133 \mathrm{~kg} / \mathrm{m}^{3}\right)$;

$V$ - total volume, in ${ }^{3}$;

$S$ - area of the exposed surface, $i^{2}$.

Eq. (3.1) is an empirical equation and the resultant temperature is given in ${ }^{\circ} \mathrm{F}$. The approximation assumes equivalent drying shrinkage of $150 \cdot 10^{-6}$ and an expansion coefficient of $9 \cdot 10^{-6} /{ }^{\circ} \mathrm{C}$.

\subsection{Restraint STRESSES}

It is defined that the stress at any point in an uncracked concrete member is proportional to the strain in concrete. The horizontal stress in a member continuously restrained at its base and subjected to an otherwise uniform horizontal length change varies from point to point in accordance with the variation in degree of restraint throughout the member. Two restraint factors have been developed to fully model the restraint conditions on a massive structure: the structural shape restraint factor $K_{R}$ and the foundation restraint factor $K_{F}$.

Distribution of the $K_{R}$ restraint varies with the length-to-height ratio $\left(L_{c} / H_{c}\right)$ of the element. The distribution of the $K_{R}$ restraint at centre section is shown in Fig. 3a. The following approximation of $K_{R}$ distribution is proposed: 


$$
K_{R}=\left\{\begin{array}{lll}
\left(\frac{L_{c} / H_{c}-2}{L_{c} / H_{c}+1}\right)^{y / H_{c}} & \text { if } & L_{c} / H_{c} \geq 2.5 \\
\left(\frac{L_{c} / H_{c}-1}{L_{c} / H_{c}+10}\right)^{y / H_{c}} & \text { if } & L_{c} / H_{c}<2.5
\end{array}\right.
$$

where $y$ signifies location above the construction joint.

a)

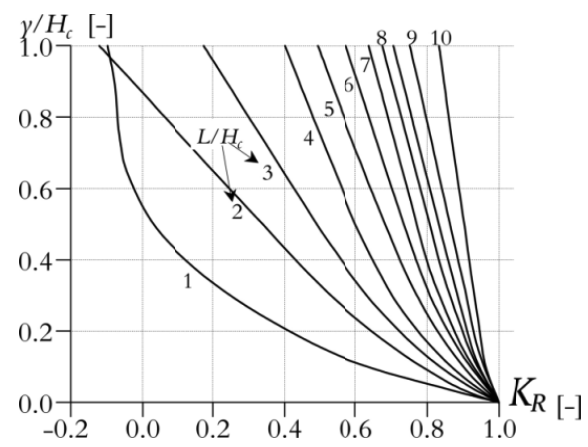

b)

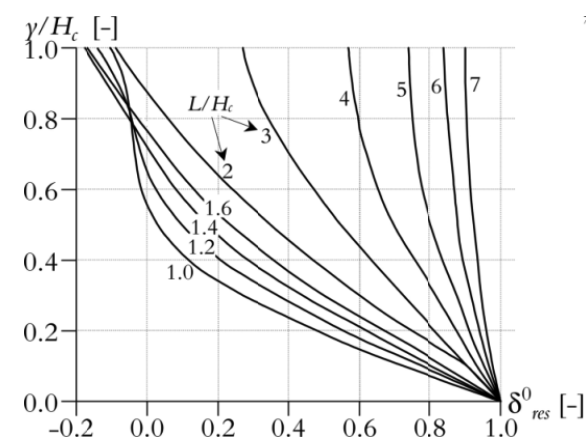

Fig. 3. a) Structural shape restraint factor $K_{R}$ at centre section [5],

b) Basic resilience factor $\delta_{\text {res }}^{0}$ at centre section [6].

The stresses in concrete due to restraint decrease in direct proportion to the decrease in stiffness of the restraining foundation material. The restraint factor $K_{F}$ has been approximated as:

$$
K_{F}=\frac{1}{1+\frac{A_{c} E_{c}}{A_{F} E_{F}}}
$$

where:

$A_{c}$ - gross area of concrete cross-section, $\mathrm{m}^{2} ;$

$A_{F}$ - area of foundation or other element restraining shortening of element, generally taken as a plane surface at contact, $\mathrm{m}^{2}$;

$E_{c}$ - modulus of elasticity of wall, GPa;

$E_{F}-$ modulus of elasticity of foundation or restraining element, GPa.

The restraint factor is hence given by the equation:

$$
\gamma_{R}=K_{R} \cdot K_{F}
$$


and tensile stress at any point on the centreline due to a decrease in length $\varepsilon_{\text {tot }}$ can be calculated as:

$$
\sigma=K_{R} \cdot K_{F} \cdot \varepsilon_{\text {tot }} \cdot E_{c m, e f f}
$$

where $E_{c m, e f f}$ signifies a sustained modulus of elasticity of concrete at the time when thermal-shrinkage strains $\varepsilon_{\text {tot }}$ occurred and for the duration involved. The value of the modulus of elasticity of concrete can be given taking into account its development in time related to the concrete temperature development as well as taking into consideration the influence of creep. Prediction of creep is discussed in ACI Report 209R, however, it is not designated to early-age concrete.

\section{LULEA UNIVERSITY OF TECHNOLOGY APPROACH}

\subsection{Temperature AND SHRINKAge-INDUCED VOlume CHANGES}

The third approach, derived at the Luleå University of Technology, Sweden, is more complex (NILSSON [6], LARSON [7]). The method focuses on estimation of cracking risk by means of determination of the restraint factor. It should be emphasised that it has not been clarified how the restraint coefficient shall be applied in a thermal stress analysis. The method does not provide instructions for determination of temperature and moisture fields. Volume change is expressed in a form of inelastic strain $\varepsilon_{\mathrm{tot}}(t)$ originating from a combination of thermal expansion $\varepsilon_{T}(t)$ and autogenous shrinkage $\varepsilon_{A D}(t)$ :

$$
\varepsilon_{\mathrm{tot}}(t)=\varepsilon_{T}(t)+\varepsilon_{A D}(t)
$$

The discussed approach suggests that parameters required for calculation of thermal and shrinkage strains depend on a concrete mix composition and should be determined from laboratory tests.

\subsection{Restraint StResses}

In this approach the decisive restraint coefficient is defined as:

$$
\gamma_{R}=\gamma_{R}\left(\gamma_{R}^{0}, \delta_{\text {res }}, \delta_{\text {slip }}\right)
$$

where:

$\gamma_{R}^{0}$ - the plane-section restraint coefficient, which depends on the geometry of the structure as well as both the rotational $\gamma_{R}^{r x}, \gamma_{R}^{r y}$ and translational $\gamma_{R}^{t}$ boundary restraints from underlying foundation materials;

$\delta_{\text {res }}$ - the resilience factor considering the non-linear effects in high walls (typically walls with $L_{c} / H_{c}<5$ where plane-section theory is no longer valid), acc. to Fig. 3b; 
$\delta_{\text {slip }}$ - the slip factor which depicts a restraint stresses reduction as a result of slip failure in casting joints (usually occurring in walls with $L_{c} / H_{c}<5$ ).

The decisive restraint coefficient distribution at height $y$ in central section of a wall can be calculated according to the following equation:

$$
\gamma_{R}=\delta_{\text {res }} \cdot \delta_{\text {slip }}-\gamma_{R}^{0}=\delta_{\text {res }} \cdot \delta_{\text {slip }}-\gamma_{R}^{t}-\gamma_{R}^{r x}-\gamma_{R}^{r y}
$$

For the walls which are not affected by the high-walls effects, the formula simplifies to:

$$
\gamma_{R}=1-\gamma_{R}^{0}
$$

The $\gamma_{R}^{0}$ coefficient is calculated based on the geometry of the wall and its foundation:

$$
\begin{aligned}
\gamma_{R}^{0}(y)= & \frac{1}{1+\frac{E_{F}}{E_{c}} \cdot \frac{H_{F} \cdot B_{F, \text { eff }}}{H_{c} \cdot B_{c}}}+\frac{\left(y_{\mathrm{cen}}-y\right) \cdot\left(y_{\mathrm{cen}}-0.5 H_{c}\right)}{\frac{H_{c}^{2}}{12}+\left(y_{\mathrm{cen}}-\frac{H_{c}}{2}\right)^{2}+\frac{E_{F}}{E_{c}} \cdot \frac{H_{F} \cdot B_{F, \text { eff }}}{H_{c} \cdot B_{c}} \cdot\left(\frac{H_{F}^{2}}{12}+\left(y_{\mathrm{cen}}+\frac{H_{F}}{2}\right)^{2}\right)^{2}}+ \\
& +\frac{\left(x_{\mathrm{cen}}-\omega \cdot 0.5\left(B_{F, \text { eff }}-B_{c}\right)\right)^{2}}{\frac{B_{c}^{2}}{12}+\left(x_{\mathrm{cen}}-\omega \cdot \frac{B_{F, \text { eff }}-B_{c}}{2}\right)^{2}+\frac{E_{F}}{E_{c}} \cdot \frac{H_{F} \cdot B_{F, \text { eff }}}{H_{c} \cdot B_{c}} \cdot\left(\frac{B_{F, \text { eff }}^{2}}{12}+x_{\mathrm{cen}}^{2}\right)}
\end{aligned}
$$

where:

$x, y \quad-$ coordinates of the analysed point, $\mathrm{m}$;

$x_{\text {cen }}, y_{\text {cen }}-$ coordinates of the centroid of transformed section (considering old and new part of the element), $\mathrm{m}$;

$H_{c} \quad-$ height of the wall, m;

$B_{c} \quad-$ thickness of the wall, $\mathrm{m}$;

$E_{c} \quad-$ modulus of elasticity of the wall at the moment of analysis, GPa;

$H_{F} \quad-$ depth of foundation, m;

$B_{F \text {,eff }} \quad$ - effective width of foundation, $\mathrm{m}$. The effective width of foundation is determined to comply with the curvature obtained in FE-analysis;

$E_{F} \quad$ - modulus of elasticity of foundation at the moment of analysis, GPa;

$\omega-$ location factor (defines relative location of the wall with respect to the central axis of foundation).

When a slip failure in the joint is possible and if the sections do not remain plane under deformation (high walls effect), the restraint in the wall is defined as: 


$$
\gamma_{R}(y)=\left(\delta_{r e s}(y)-\frac{\sum_{i=1}^{n} \frac{a_{i}}{i+1}}{1+\frac{E_{F}}{E_{c}} \cdot \frac{H_{F} \cdot B_{F, e f f}}{H_{c} \cdot B_{c}}}-\frac{\left(y_{c e n}-y\right) \cdot\left(y_{c e n} \cdot \sum_{i=1}^{n} \frac{a_{i}}{i+1}-H_{c} \cdot \sum_{i=1}^{n} \frac{a_{i}}{i+2}\right)}{\frac{H_{c}^{2}}{12}+\left(y_{\text {cen }}-\frac{H_{c}}{2}\right)^{2}+\frac{E_{F}}{E_{c}} \cdot \frac{H_{F} \cdot B_{F, e f f}}{H_{c} \cdot B_{c}} \cdot\left(\frac{H_{F}^{2}}{12}+\left(y_{c e n}+\frac{H_{F}}{2}\right)^{2}\right)}-\right.
$$

$$
\left.-\frac{\left(x_{c e n}-\omega \cdot 0.5\left(B_{F, e f f}-B_{c}\right)\right)^{2}}{\frac{B_{c}^{2}}{12}+\left(x_{c e n}-\omega \cdot \frac{B_{F, e f f}-B_{c}}{2}\right)^{2}+\frac{E_{F}}{E_{c}} \cdot \frac{H_{F} \cdot B_{F e f f}}{H_{c} \cdot B_{c}} \cdot\left(\frac{B_{F, e f f}^{2}}{12}+x_{c e n}^{2}\right)}\right) \cdot \delta_{s l i p}
$$

where $a_{i}$ are coefficients of polynomial function describing resilience factor distribution.

Tensile stress can be calculated as:

$$
\sigma=\gamma_{R} \cdot \sigma^{\mathrm{fix}}
$$

The fixation stress is given by a formula:

$$
\sigma^{\mathrm{fix}}(t)=-\int_{t} R\left(t, t_{0}\right) \cdot \mathrm{d} \varepsilon_{t o t}(t)
$$

where $R\left(t, t_{0}\right)$ is a relaxation function at time $t$ for loading at the age $t_{0}$ (in equivalent time determined acc. to Arrhenius equation). For a known creep function $\varphi\left(t, t_{0}\right)$ it may be expressed as:

$$
R\left(t, t_{0}\right)=E_{c m}(t) \cdot\left(1-\frac{\varphi\left(t, t_{0}\right)}{1+\chi \cdot \varphi\left(t, t_{0}\right)}\right)
$$

where $\chi$ is the ageing coefficient. The proposed creep function was derived from Linear Logarithmic Model, broadly described by LARSON [7], with parameters to be evaluated from laboratory tests.

The development of modulus of elasticity is defined as:

$$
E_{c m}(t)=E_{c m} \cdot \beta_{E}(t)
$$

where $E_{c m}$ is the 28-day modulus of elasticity of concrete and $\beta_{E}(t)$ is the relative development expressed as a function of equivalent ages, with parameters to be evaluated from laboratory tests. 


\section{COMPaRison OF ANALYTICAL MODELS: ANALYSIS OF RC WALLS}

\subsection{Material, technological AND GeOMEtrical data}

In the analysis the distribution of thermal stresses of six walls was investigated. The walls differed in dimensions: walls of thickness 40 and $70 \mathrm{~cm}$ and length of 8,16 and $28 \mathrm{~m}$. Geometrical characteristics of the analysed walls are presented in Table 1. According to classification proposed by FLAGA [9] all the walls are medium-thick elements in which expected temperature rise should not exceed $20^{\circ} \mathrm{C}$. Moreover, the same value of thermal-moisture influence measure in a form of apparent surface modulus/equivalent thickness for the walls with the same thickness suggests that the expected self-induced part of thermal-shrinkage stress will be of similar magnitude. On the other hand, when analysing the linear restraint expressed in a form of length-to-height ratio of the wall, $L_{c} / H_{c}$, distribution of total stress (encountering restraint part of stress) should differ between the walls with different $L_{c} / H_{c}$ and higher restraint stresses will be observed in thinner walls due to relatively greater stiffness of restraining foundation.

Concrete class C25/30 was assumed for both the wall and the foundation. For the foundation the material properties were assumed as for 28-day concrete. For the wall, development of material properties in time considering influence of temperature and creep was assumed. Detailed material properties, environmental and technological conditions are listed in Table 1, while parameters for numerical, thermal analysis are given in Table 2.

\subsection{Thermal ANALYsis}

The analysis focused on structural behaviour of the walls due to the influence of thermal effects because this part of the analysis was common for all the presented methods and as such allows of comparison. To compare the methods, temperature development was determined by means of numerical analysis with use of program TEMWIL developed by KLEMCZAK [10]. It was observed that temperature development and distribution in the centre cross-section of the wall depends only on the thickness of the wall. Figure 4a presents the map of thermal fields at the moment of reaching of the maximum hardening temperature in a chosen wall. It can be observed that concentration of high temperature occurs in the central part of the wall while because of heat dissipation the values of temperature decrease towards the exposed surfaces. Figure $4 \mathrm{~b}$ presents diagrams of temperature development in time in the location where the maximum temperature is observed in the wall, i.e. in its central part. It can be noticed that the maximum hardening temperatures in the walls were equal to $37.3^{\circ} \mathrm{C}$ after 1.5 days in $70-\mathrm{cm}$ thick walls and $32.9^{\circ} \mathrm{C}$ after 1.1 days in $40-\mathrm{cm}$ thick walls. 
Table 1

Geometrical, material and technological data for the analysed walls

\begin{tabular}{|c|c|c|c|c|c|c|c|}
\hline & & & & & & \\
\hline & & L_28,d_0.4 & L_16,d_0.4 & L_8,d_0.4 & L_28,d_0.7 & L_16,d_0.7 & L_8,d_0.7 \\
\hline \multicolumn{8}{|c|}{ GEOMETRICAL DATA } \\
\hline \multirow{3}{*}{ wall } & thickness $B_{c}[\mathrm{~m}]$ & & \multicolumn{3}{|c|}{0.4} & \multicolumn{2}{|c|}{0.7} \\
\hline & length $L_{c}[\mathrm{~m}]$ & 28 & 16 & 8 & 28 & 16 & 8 \\
\hline & height $H_{c}[\mathrm{~m}]$ & \multicolumn{6}{|c|}{4} \\
\hline \multirow{3}{*}{ foundation } & depth $H_{F}[\mathrm{~m}]$ & \multicolumn{6}{|c|}{0.7} \\
\hline & length $L_{F}[\mathrm{~m}]$ & 28 & 16 & 8 & 28 & 16 & 8 \\
\hline & width $B_{F}[\mathrm{~m}]$ & \multicolumn{6}{|c|}{4} \\
\hline \multirow{2}{*}{$\begin{array}{l}\text { geometrical } \\
\text { characteristics }\end{array}$} & $L_{c} / H_{c}$ & & 7 & 4 & 2 & 7 & 4 \\
\hline & $A_{F} / A_{c}$ & \multicolumn{3}{|c|}{1.75} & \multicolumn{3}{|c|}{1.00} \\
\hline \multicolumn{8}{|c|}{ MATERIAL DATA } \\
\hline \multirow{2}{*}{ concrete } & class & \multicolumn{6}{|c|}{$\mathrm{C} 25 / 30$} \\
\hline & $\alpha_{T}$ & \multicolumn{6}{|c|}{$0.00001 /{ }^{\circ} \mathrm{C}$} \\
\hline \multirow{5}{*}{ mix comp. } & water & \multicolumn{6}{|c|}{$170 \mathrm{l} / \mathrm{m}^{3}$} \\
\hline & cement & \multicolumn{6}{|c|}{ CEM III $42.5 \mathrm{~N}, 350 \mathrm{~kg} / \mathrm{m}^{3}$} \\
\hline & fine aggregate & \multicolumn{6}{|c|}{ sand, $675 \mathrm{~kg} / \mathrm{m}^{3}$} \\
\hline & coarse aggregate & \multicolumn{6}{|c|}{ (rounded aggregate) dolomite, $1139 \mathrm{~kg} / \mathrm{m}^{3}$} \\
\hline & $\begin{array}{r}\text { additives \& } \\
\text { admixtures }\end{array}$ & \multicolumn{6}{|c|}{$6 \mathrm{~kg} / \mathrm{m}^{3}$} \\
\hline \multirow{3}{*}{$\begin{array}{l}\text { 28-days } \\
\text { mechanical } \\
\text { properties }\end{array}$} & $f_{c m}$ & \multicolumn{6}{|c|}{$33 \mathrm{MPa}$} \\
\hline & $f_{\text {ctm }}$ & \multicolumn{6}{|c|}{$2.6 \mathrm{MPa}$} \\
\hline & $E_{c m}$ & \multicolumn{6}{|c|}{$31 \mathrm{GPa}$} \\
\hline \multicolumn{8}{|c|}{ TECHNOLOGICAL DATA } \\
\hline \multirow{3}{*}{$\begin{array}{l}\text { environmental } \\
\text { characteristics }\end{array}$} & \begin{tabular}{|c|} 
ambient temper- \\
ature $T_{a}$ \\
\end{tabular} & \multicolumn{6}{|c|}{$20^{\circ} \mathrm{C}$} \\
\hline & $\begin{array}{c}\text { relative humidi- } \\
\text { ty } R H \\
\end{array}$ & \multicolumn{6}{|c|}{$60 \%$} \\
\hline & wind velocity $v$ & \multicolumn{6}{|c|}{$4 \mathrm{~m} / \mathrm{s}$} \\
\hline technological & $\begin{array}{l}\text { initial temp. of } \\
\text { concrete mix } T_{i} \\
\end{array}$ & & & $20^{\circ} \mathrm{C}$ & & & \\
\hline characteristics & formwork & $1.8-\mathrm{cm}$ plyv & $\begin{array}{r}\text { wood on side } \\
p\end{array}$ & $\begin{array}{l}\text { surfaces, re } \\
\text { orotected wi }\end{array}$ & $\begin{array}{l}\text { emoved afte } \\
\text { th PE foil }\end{array}$ & 28 days, to & op surface \\
\hline
\end{tabular}


Table 2

Parameters for numerical analysis (temperature fields)

\begin{tabular}{|c|c|}
\hline Coefficient of thermal conductivity $\lambda$ & $3.23 \mathrm{~W} /(\mathrm{mK})$ \\
\hline Specific heat $c_{b}$ & $1.0 \mathrm{~kJ} /(\mathrm{kgK})$ \\
\hline Density of concrete $\rho$ & $2340 \mathrm{~kg} / \mathrm{m}^{3}$ \\
\hline Thermal transfer coefficient $\alpha_{p}$ & $\begin{array}{c}\text { without protection } 15.00 \mathrm{~W} /\left(\mathrm{m}^{2} \mathrm{~K}\right) \\
1.8-\mathrm{cm} \text { plywood formwork } 5.58 \mathrm{~W} /\left(\mathrm{m}^{2} \mathrm{~K}\right) \\
\text { PE foil } 13.78 \mathrm{~W} /\left(\mathrm{m}^{2} \mathrm{~K}\right)\end{array}$ \\
\hline Heat of hydration $Q(T, t)$ & $\begin{array}{c}\text { Acc. to equation for CEM III } 42.5 \mathrm{~N}: \\
Q_{\infty} \mathrm{e}^{-a t_{e}^{-0.5}} \text { where } Q_{\infty}=469 \mathrm{~kJ} / \mathrm{kg}, a=475.7 t_{e}^{-0.093}\end{array}$ \\
\hline
\end{tabular}

a)

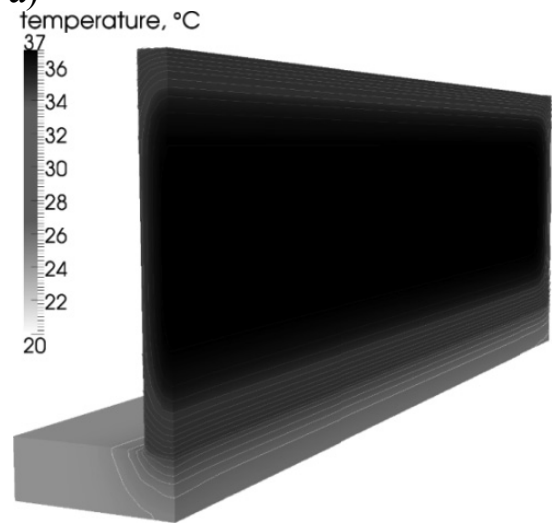

b)

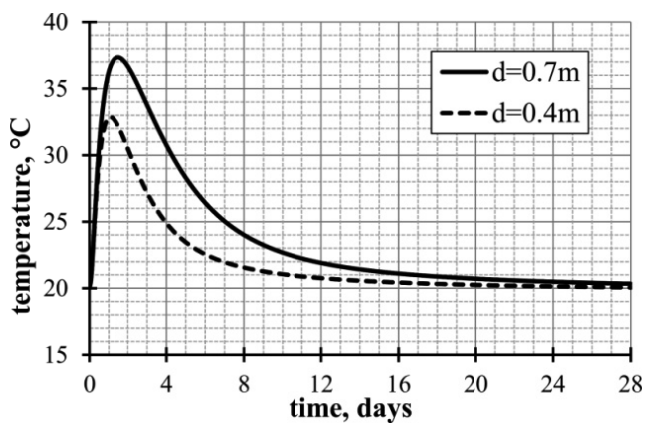

Fig. 4. Distribution of temperature in the wall: a) map of thermal fields $\left(1 / 4\right.$ of the $L \_28, d \_0.7$ wall $)$ at the moment of reaching the maximum hardening temperature, b) diagram of temperature development in time - the centre section for the L_28 wall with $0.7 \mathrm{~m}$ and $0.4 \mathrm{~m}$ thickness.

\subsection{THermal STRESSES}

The analysis of structural behaviour of the investigated walls focused on determination of total thermal stress distribution, especially the influence of restraint stresses, in the centre section of the wall according to the presented analytical methods. Tensile stresses were determined from tensile strains resulting from contraction of the wall in the cooling phase and the computed degree of restraint. Temperature development was taken from the numerical analysis. Thermal strain change in any location in the centre section of the wall above the joint $y$ in a time step $\Delta t$ when temperature difference $\Delta T$ was observed was calculated as: 


$$
\Delta \varepsilon_{T}(\Delta t, y)=\Delta T(\Delta t, y) \cdot \alpha_{T}
$$

and tensile fixation stress in any time $t$ as:

$$
\sigma^{\mathrm{fix}}(t, y)=\sum_{i}\left(\Delta \varepsilon_{T, i}(\Delta t, y) \cdot E_{c m, e f f, \text { mean }, i}(\Delta t, y)\right)
$$

where $E_{c m, e f f, \text { mean }, i}$ signifies mean sustained modulus of elasticity of concrete in a $i^{\text {th }}$ time step. Development of the modulus of elasticity in time was calculated acc. to Eq. (2.3). The effect of increased temperature was neglected to apply equal values of the moduli. The influence of creep was considered by reduction of modulus of elasticity of concrete (KIERNOŻYCKI [11]):

$$
E_{c m, e f f}(t)=\frac{E_{c m}(t)}{1+\beta_{1} \cdot \varphi_{p}\left(t_{r}, t_{0}\right)}
$$

where:

$\beta_{1} \quad$ - ageing coefficient, can be taken as 0.8 ;

$\varphi_{p}\left(t_{r}, t_{0}\right)$ - creep coefficient, can be taken as 0.6 .

The total thermal stress at any time $t$ and any location $y$ on a centreline was calculated as:

$$
\sigma(t, y)=\gamma_{R}(t, y) \cdot \sigma^{\mathrm{fix}}(t, y)
$$

where $\gamma_{R}$ is a restraint factor acc. to Eq. (2.2), (3.2) and (4.1), for EC2, ACI and Luleå approach, respectively. In order to compare qualitatively the results obtained with different methods the effect of rotational restraint in the definition of the restraint factor was neglected.

\subsubsection{Uniform temperature distribution}

In the first approach, a uniform distribution of temperature in the whole volume of the wall was assumed. Development of temperature in the walls was assumed as given in diagram in Fig. 5d. Stresses were determined after 28 days.

Firstly, in each case thermal strain was calculated for total temperature change during cooling, i.e. $\Delta T=T_{\max }-T_{28 \mathrm{~d}}$ which was equal to $\Delta T=17.0^{\circ} \mathrm{C}$ for $70-\mathrm{cm}$ thick and $12.8^{\circ} \mathrm{C}$ for 40 -cm thick walls. The resulting thermal strains were equal to $\varepsilon_{T}=17.0 \cdot 10^{-5}$ and $12.8 \cdot 10^{-5}$, respectively. If the mean values of moduli of elasticity were taken $-E_{c m, \text { eff,mean }}=17.39 \mathrm{GPa}$ for $70-\mathrm{cm}$ thick walls and $16.76 \mathrm{GPa}$ for $40-\mathrm{cm}$ thick walls - the resulting fixation stresses were equal to $\sigma^{\mathrm{fix}}=2.96 \mathrm{MPa}$ and $2.15 \mathrm{MPa}$. For the final, 28-day values of the moduli $\left(E_{c m, e f f, 28}=20.95 \mathrm{GPa}\right)$ the fixation stresses were 
equal to $\sigma^{\mathrm{fix}}=3.56 \mathrm{MPa}$ and $2.68 \mathrm{MPa}$. Secondly, thermal strains were numerically integrated in the cooling phase (after the maximum temperature occurs) in time steps $\Delta t=2$ hours. In each step a temperature difference was determined and a resulting strain was computed. A mean value of the modulus of elasticity was taken in each step, too. The final values of fixation stresses after 28 days were equal to $2.03 \mathrm{MPa}$ for $40-\mathrm{cm}$ thick walls and $2.99 \mathrm{MPa}$ for $70-\mathrm{cm}$ thick walls. This yields the question of how to assume the mean value of the modulus of elasticity in manual calculations when total strain is considered.

a)

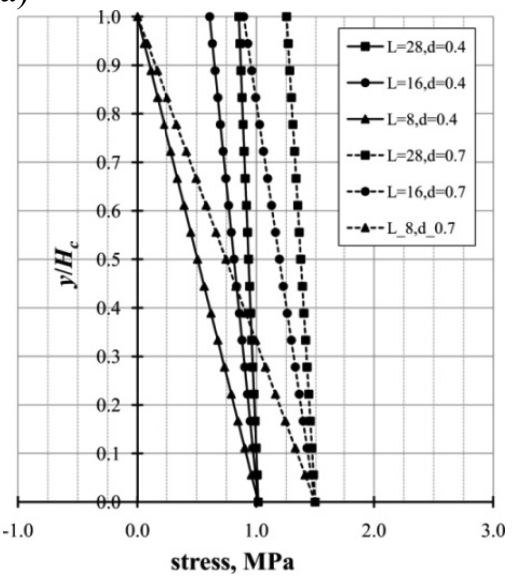

c)

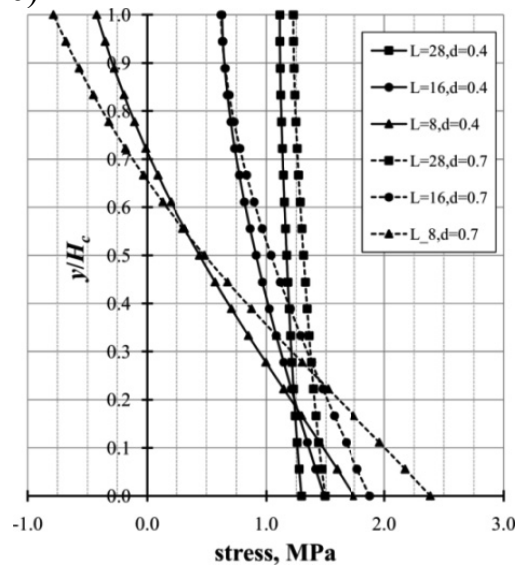

b)

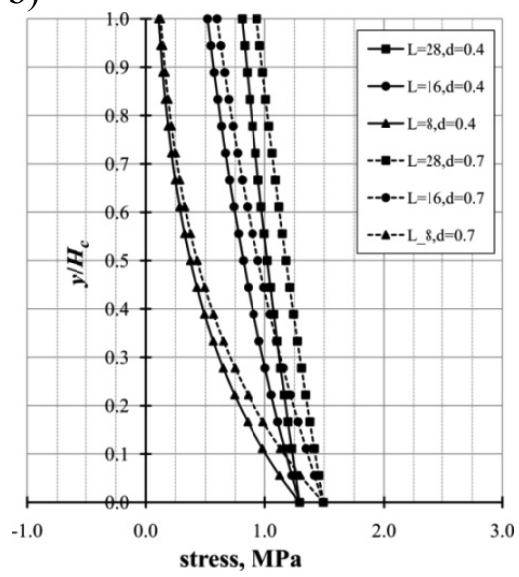

d)

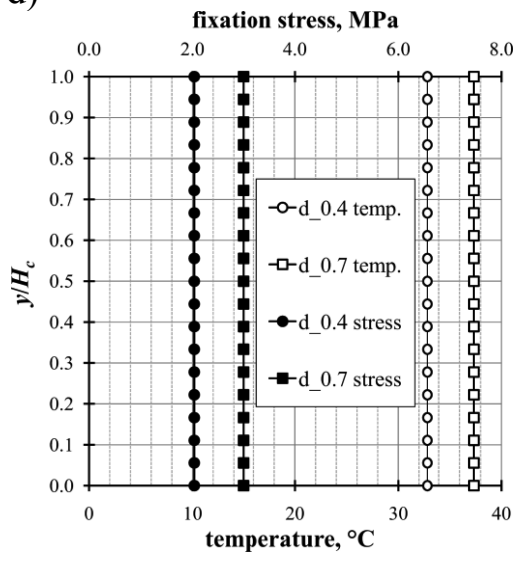

Fig. 5. The case of uniform distribution of temperature: distribution of total thermal stress in centre crosssection of the walls according to EC2 (a), ACI (b) and Luleå (c) method, d) assumed uniform temperature at the height of the wall (at the moment of reaching the maximum hardening temperature) and fixation stress distribution for the walls with $0.4 \mathrm{~m}$ and $0.7 \mathrm{~m}$ thickness. 
Total stresses were calculated with use of the restrain factor according to Eq. (5.1), for the final values of fixation stresses after 28 days equal to $2.03 \mathrm{MPa}$ for $40-\mathrm{cm}$ thick walls and $2.99 \mathrm{MPa}$ for $70-\mathrm{cm}$ thick walls. Distribution of stresses at the height of the walls was presented in Fig. 5. Table 3 presents the values of the restraint factor and total stress at the bottom and top of the walls. Comparing the results obtained by means of all methods a tendency can be observed that with the increasing $L_{c} / H_{c}$ ratio the influence of the restraint at the height decreases - upper fibres are allowed to deform more freely. Nevertheless, some differences may be also noticed.

Table 3

Restraint factor and total thermal stress in chosen locations of the walls acc. to different methods

\begin{tabular}{|c|l|c|c|c|c|c|c|}
\cline { 3 - 8 } \multicolumn{2}{c|}{} & \multicolumn{2}{c|}{ EC2 } & \multicolumn{2}{c|}{ ACI } & \multicolumn{2}{c|}{ Luleå } \\
\cline { 3 - 8 } \multicolumn{2}{c|}{} & $\gamma_{R}$ & $\sigma^{\mathrm{fix} \cdot} \gamma_{R}[\mathrm{MPa}]$ & $\gamma_{R}$ & $\sigma^{\mathrm{fix} \cdot \gamma_{R}}[\mathrm{MPa}]$ & $\gamma_{R}$ & $\sigma^{\mathrm{fix} \cdot \gamma_{R}[\mathrm{MPa}]}$ \\
\hline \multirow{3}{*}{ L_8,d_0.4 } & $y=0$ & 0.500 & 1.074 & 0.636 & 1.294 & 0.854 & 1.736 \\
\cline { 2 - 8 } & $y=H_{c}$ & 0.000 & 0.000 & 0.053 & 0.108 & -0.208 & -0.423 \\
\hline \multirow{2}{*}{ L_16,d_0.4 } & $y=0$ & 0.500 & 1.074 & 0.636 & 1.294 & 0.730 & 1.485 \\
\cline { 2 - 8 } & $y=H_{c}$ & 0.300 & 0.644 & 0.255 & 0.518 & 0.309 & 0.628 \\
\hline \multirow{3}{*}{ L_28,d_0.4 } & $y=0$ & 0.500 & 1.074 & 0.636 & 1.294 & 0.636 & 1.294 \\
\cline { 2 - 8 } & $y=H_{c}$ & 0.420 & 1.902 & 0.398 & 0.809 & 0.547 & 1.113 \\
\hline \multirow{2}{*}{ L_8,d_0.7 } & $y=0$ & 0.500 & 1.481 & 0.500 & 1.493 & 0.799 & 2.385 \\
\cline { 2 - 8 } & $y=H_{c}$ & 0.000 & 0.000 & 0.042 & 0.124 & -0.263 & -0.785 \\
\hline \multirow{2}{*}{ L_16,d_0.7 } & $y=0$ & 0.500 & 1.481 & 0.500 & 1.493 & 0.629 & 1.877 \\
\cline { 2 - 8 } & $y=H_{c}$ & 0.300 & 0.888 & 0.200 & 0.597 & 0.208 & 0.621 \\
\hline \multirow{2}{*}{ L_28,d_0.7 } & $y=0$ & 0.500 & 1.481 & 0.500 & 1.493 & 0.500 & 1.493 \\
\cline { 2 - 8 } & $y=H_{c}$ & 0.420 & 1.244 & 0.313 & 0.933 & 0.411 & 1.227 \\
\hline
\end{tabular}

The results of the EC2 show a visible and straightforward difference in the values of stresses reached in the walls of different thicknesses - the maximum value of stress depends only on the thickness of the wall (the fixation stress). This results from the fact that the restraint factor in such an approach depends only on the $L_{c} / H_{c}$ ratio and the influence of relative foundation stiffness is not considered. A similar observation can be made in case of the stress distribution obtained with use of ACI method, however, the differences in stresses between the walls of different thicknesses are lower. This can be explained by the fact that although higher fixation stresses can be expected in thicker walls the restraint exerted by the foundation is in this case lower so the resultant total stresses differ by a smaller magnitude.

In the results obtained with the Lulea approach a strong influence of both the thickness (fixation stresses and relative stiffness of foundation) and length $\left(L_{c} / H_{c}\right.$ ratio) is 
visible. It can be summarised that in the walls with lower $L_{c} / H_{c}$ ratio the effect of the restraint concentrates near the joint; in contrary, in the walls with higher $L_{c} / H_{c}$ ratio the effect of the restraint is more uniform at the whole height of the wall. Hence, this approach can be treated as an extension to previous methods.

\subsubsection{Non-uniform distribution of temperature}

Calculations were made according to the procedure presented in section 5.3.1 but taking into consideration real distribution of temperature at the height of the wall. As real thermal fields are non-stationary fields (temperature differs from point to point), a semi-numerical approach was required in which the wall was divided into a finite number of segments with the same value of temperature assigned. The calculations were made for two walls - the L_28,d_0.7 wall and the L_16,d_0.7 wall. Distribution of maximum temperature arising in the wall and resulting fixation stresses are presented in Fig. $6 \mathrm{a}$ and Fig. 7a. Total thermal stresses along the height of the walls and the restraint factors distribution are shown in Fig. 6b, c and 7b, c. This analysis is focused on determination of the decisive point.

Total thermal stresses are a combination of self-induced stresses, caused by temperature differences, and restraint stresses, caused by the influence of a linear restraint of foundation. As it can be observed in diagrams in Fig. 6 and 7, the restraint coefficient is a measure that defines inclination of the total stress curve in cross-section. Therefore, if the value of the restraint coefficient is more uniform - which is characteristic for the walls with high $L_{c} / H_{c}$ ratio - total stress distribution is also more uniform, qualitatively similar to fixation stress. Nevertheless, as fixation stresses decrease towards the edges of the wall, the maximum value of the total stress is not observed at the wall-foundation joint but at some height above the joint referred to as a decisive point.

The locations of the decisive points and the values of stresses in this locations are presented in Table 4. The results obtained with Lulea approach give the highest values of total stresses, especially concerning the stress in the decisive point, because of the high values of the restraint assumed. The lowest values are obtained with use of the ACI approach. No direct relationship between the approach and the location of the decisive point can be made because the influence of the restraint caused by the relative stiffness of the foundation is included in a different manner than in the other methods. In the Luleå approach it is suggested that the decisive point can be assumed one wall thickness above the joint and this is satisfied by the results obtained with use of this method. Nevertheless, the location of the decisive point varies from case to case. In general it can be said that for the walls which differ only in geometry of the wall the decisive point is located the closest to the joint in thinner walls with low $L_{c} / H_{c}$ ratio and is being observed higher as the thickness of the wall and $L_{c} / H_{c}$ ratio increase. That tendency in visible in the EC2 and ACI approach. 
a)

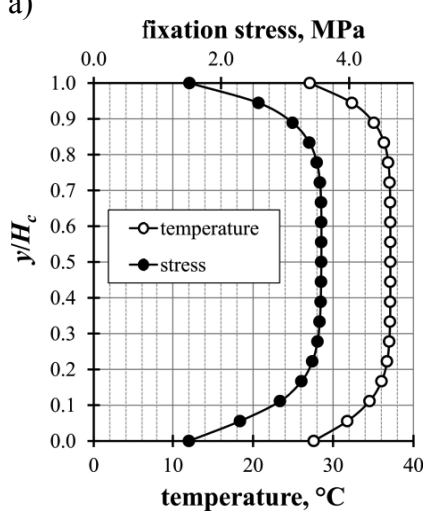

b)

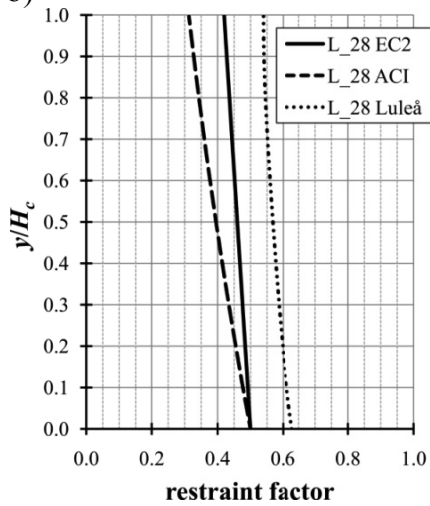

c)

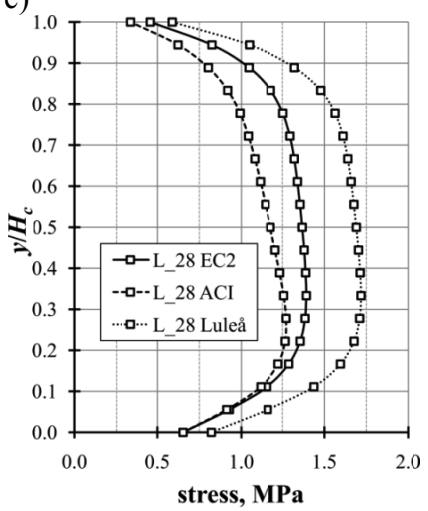

Fig. 6. The case of non-uniform distribution of temperature - wall L_28,d_0.7: a) distribution of temperature at the height of the wall (at the moment of reaching the maximum hardening temperature) and fixation

thermal stress, b) restrain factor at the height, c) total thermal stress at the height after 28 days.

a)

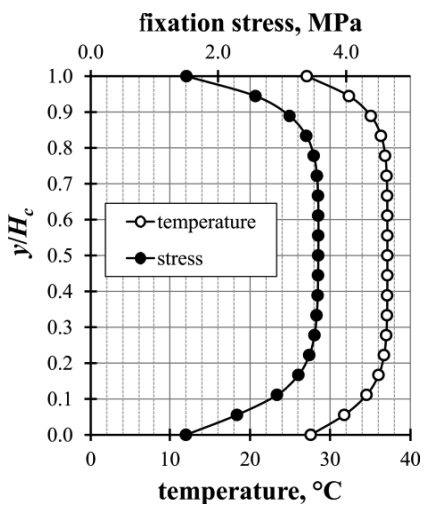

b)

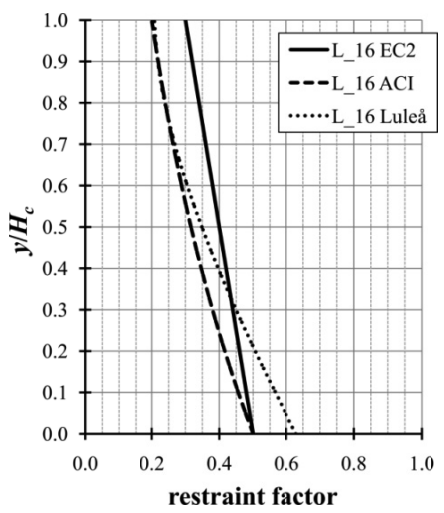

c)

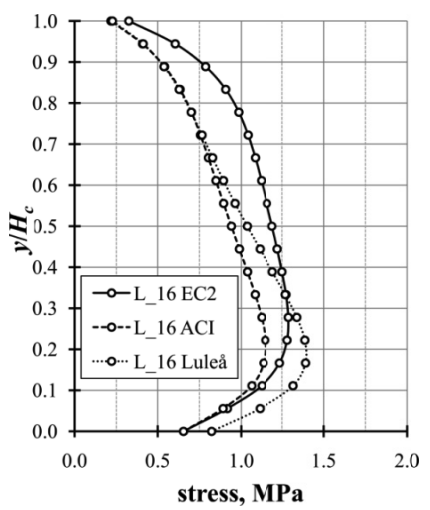

Fig. 7. The case of non-uniform distribution of temperature - wall L_16,d_0.7: a) distribution of temperature at the height of the wall (at the moment of reaching the maximum hardening temperature) and fixation thermal stress, b) restrain factor at the height, c) total thermal stress at the height after 28 days

Table 4

Decisive points acc. to different methods: location and the value of total stress

\begin{tabular}{|c|c|c|c|c|c|c|}
\cline { 2 - 7 } \multicolumn{1}{c|}{} & \multicolumn{2}{c|}{ EC2 } & \multicolumn{2}{c|}{ ACI } & \multicolumn{2}{c|}{ Luleå } \\
\cline { 2 - 7 } & $y[\mathrm{~m}]$ & $\sigma(y)[\mathrm{MPa}]$ & $y[\mathrm{~m}]$ & $\sigma(y)[\mathrm{MPa}]$ & $y[\mathrm{~m}]$ & $\sigma(y)[\mathrm{MPa}]$ \\
\hline L_16,d_0.7 & 1.1 & 1.289 & 0.9 & 1.147 & 0.7 & 1.392 \\
\hline L_28,d_0.7 & 1.3 & 1.393 & 1.1 & 1.127 & 0.7 & 1.670 \\
\hline
\end{tabular}




\section{Conclusions}

Estimation of cracking risk in concrete elements is crucial to ensure their durability and functionality. In case of early-age concrete elements this task is especially difficult because of a complex nature of the material and imposed loading. For years analytical methods were being developed to assess the character and values of tensile stresses occurring in the phase of concrete element cooling. The derived methods are based on the concept of the restraint factor. In this paper the most known approaches are described and analysed: the method proposed in EC2 [4], the method proposed by ACI Committee 207 [5] and the method developed at the Luleå University of Technology [6, 7]. The results obtained for the walls with use of these methods are compared. The following conclusions can be drawn from the analysis:

- the procedure proposed by Eurocode 2 is a useful method under the assumption that the problem can be reduced to a planar problem, the restraining element is indeformable and that total rotational restraint exists. For broader use of the method some parameters, such as the actual restraint or spatial thermal-moisture fields must be determined which is possible either numerically or by tests;

- the procedure proposed by ACI report is a simple approach which easily provides a designer with estimation of structural behaviour of an externally restraint concrete element. Nevertheless, the resultant stresses reach relatively low values in comparison to other analytical methods so its quantitative validity should be controlled;

- the procedure proposed by the Lulea team is the most complex because it takes into consideration a great number of factors. In the most simplified form it can be easily applied for manual calculations, however, more extensive application requires computer-aided calculations or tests. The approach in a present form may pose some difficulties to a potential user but it has a great potential and should be further investigated;

- definition of the decisive point is vital for sane application of analytical approaches. The location of the decisive point varies from case to case and is proposed to be assumed one wall thickness above the joint (NILSSON [6]), however, it changes not only with the thickness but also with the $L_{c} / H_{c}$ of the element (KLEMCZAK, KNOPPIK-WRÓBEL [1]). Quantitative definition of the decisive point location is required;

- the values and the distribution of stresses at the height of the wall depend not only on the applied analytical method but also on the assumed distribution of temperature at the height of the wall. Two cases are discussed in the paper. In the first approach, a uniform distribution of temperature at the height of the wall was assumed - such assumption is commonly used in analytical methods because in these methods the temperature rise in the element is also estimated in a simplified way. In the second approach, real distribution of temperature at the height of the wall was considered. It is worth mentioning that stress distributions obtained from the second approach are in good conformity with the results from the numerical tests (KLEMCZAK, KNOPPIK-WRÓBEL [1]). Such an assumption enables precise analysis of total stress distri- 
bution but the knowledge of temperature distribution yields necessity of numerical calculations;

- the further research should focus on verification of the results obtained with different analytical methods with laboratory and numerical tests.

\section{AcKNowledgements}

This paper was done as a part of a research project N N506 043440 "Numerical prediction of cracking risk and methods of its reduction in massive and medium-thick concrete structures" funded by Polish National Science Centre. Co-author of this paper A. Knoppik-Wróbel is a scholar under the project "SWIFT" POKL.08.02.01-24-005/10 co-financed with the European Union.

\section{REFERENCES}

1. B. Klemczak, A. KnoppiK-Wróbel, Analiza naprężeń w ścianie żelbetowej poddanej wczesnym wptywom termiczno-skurczowym (Analysis of stresses in reinforced concrete wall subjected to early-age thermal-shrinkage effects). Zeszyty Naukowe Politechniki Rzeszowskiej. Budownictwo i Inżynieria Środowiska, 59, 3, 85-92, 2012.

2. A. KNoppiK-WróBel, The influence of self-induced and restraint stresses on crack development in reinforced concrete wall subjected to early-age thermal-shrinkage effects. Proceedings of 14th International Conference of Postgraduate Students Juniorstav, 162, Brno 2012.

3. M. ZYch, Analiza pracy ścian zbiorników żelbetowych we wczesnym okresie dojrzewania betonu $w$ aspekcie ich wodoszczelności (Analysis of work of RC tank walls in early ages of concrete curing in the view of their water tightness), PhD Thesis, Faculty of Civil Engineering, Cracow Technical University, 2011.

4. EN 1992-3. Eurocode 2 - Design of concrete structures - Part 3: Liquid retaining and containment structures.

5. ACI Committee 207. Report on Thermal and Volume Change Effects on Cracking of Mass Concrete (ACI 207.2R-07). ACI Manual of Concrete Practice, Part 1, 2011.

6. M. Nilsson, Restraint factors and partial coefficients for crack risk analyses of early age concrete Structures. PhD Thesis, Luleå University of Technology, 2003.

7. M. LARSON, Thermal crack estimation in early age concrete: models and methods for practical application. PhD Thesis, Luleå University of Technology, 2003.

8. EN 1992-1-1. Eurocode 2 - Design of concrete structures - Part 1-1: General rules and rules for buildings.

9. K. Flaga, Naprężenia skurczowe i zbrojenie przypowierzchniowe w konstrukcjach betonowych (Shrinkage stresses and surface reinforcement in concrete structures). Monograph 295, Wydawnictwo Politechniki Krakowskiej, Kraków 2011.

10. B. Klemczak, Prediction of Coupled Heat and Moisture Transfer in Early-Age Massive Concrete Structures. Numerical Heat Transfer. Part A: Applications, 3, 212-233, 2011.

11. W. KIERNOŻYCKI, Betonowe konstrukcje masywne (Massive concrete structures). Wydawnictwo Polski Cement, Kraków 2003. 